\title{
Birinci Basamakta Dispepsi Şikayeti Olan Erişkin Hastaya Klinik Yaklaşım
}

\section{Clinical Approach to Adult Patients with Dyspepsia in Primary Health Care}

\author{
Erkut Etçioğlu' ${ }^{1}$, Abdülkadir Aydın² \\ ${ }^{1}$ Sakarya Üniversitesi Tip Fakültesi Aile Hekimliği Anabilim Dall, Sakarya, Türkiye \\ ${ }^{2}$ Sakarya Üniversitesi Eğitim ve Araştırma Hastanesi Aile Hekimliği, Sakarya, Türkiye
}

Yazışma Adresi / Correspondence:

\section{Erkut Etçioğlu}

Sakarya Üniversitesi Tip Fakültesi, Aile Hekimliği Anabilim Dalı, Korucuk Mahallesi Konuralp Bulvarı No:81/1 Korucuk Kampüsü, Adapazarı/Sakarya T: +905535747837Ｅ-mail: erkutetcioglu@gmail.com

Geliş Tarihi / Received : 02.06.2020 Kabul Tarihi / Accepted : 30.06.2020

Orcid:

Erkut Etçioğlu https://orcid.org/0000-0002-8117-7929

Abdülkadir Aydin https://orcid.org/0000-0003-0663-586X

( Sakarya Tip Dergisi / Sakarya Med J 2020, 10(Özel Say1):69-75) DOI: 10.31832/smj.747308

Öz

Dispepsi; üst abdominal veya retrosternal bölgede ağrı, rahatsızık duygusu olarak tanımlanır, kapsamlı ayırıcı tanılara sahip ve çok bileșenli patofizyolojik mekanizmaları olan yaygın bir semptom veya semptomlar birlikteliğidir. Dispepsi șikayeti birinci basamak sağlık merkezine yapılan bașvuruların önemli bir çoğunluğunu olușturmaktadır ve büyük bir kısmında altta yatan organik bir neden bulunamaz. Dispepsi hastalarının yaklaşık yüzde $25^{\prime}$ inde altta yatan organik bir nedeni vardır, ancak hastaların yüzde $75^{\prime}$ inde altta yatan organik bir neden olmayan fonksiyonel dispepsi vardır. Bazı hastalıklar sadece dispepsi şikayeti ile ortaya çıkabilir ve birinci basamak hekimleri tarafından şüphelenilen durumda mutlaka endoskopik değerlendirme ve ileri tetkik için ilgili uzman hekime yönlendirilmelidir.

Anahtar Dispepsi; Temel Sağlık Hizmeti; Aile Hekimliği

Kelimeler

Abstract

Dyspepsia is defined as pain and discomfort in the upper abdominal or retrosternal region and combination of symptoms with comprehensive differential diagnoses and multicomponent pathophysiological mechanisms. Dyspepsia constitutes a significant majority of the applications made to the primary health care center and most of them cannot have an underlying organic cause. Approximately 25 percent of patients with dyspepsia have an underlying organic cause however 75 percent of patients have functional dyspepsia with no underlying organic cause. Some diseases can only occur with the complaint of dyspepsia, and in case of suspected by primary care physicians, they should be directed to the related specialist for endoscopic evaluation and further examination.

Keywords Dyspepsia; Primary Health Care; Family Practice 


\section{GIIRIș}

Dispepsi üst abdominal veya retrosternal bölgede ağrı, rahatsızlık duygusu olarak tanımlanır. ${ }^{1}$ Rahatsızlık duygusu ise defekasyonla rahatlamayan şişkinlik, erken doyma, tokluk duygusu ve bulantı gibi subjektif yakınmaları içerir. ${ }^{2}$ Dispepsi, kapsamlı ayırıcı tanılara sahip ve çok bileşenli patofizyolojik mekanizmaları olan yaygın bir semptom veya semptomlar birlikteliğidir.

Dünya nüfusunun en az yüzde 20'sinde bu semptomun görüldüğü, ancak herhangi bir tedavi almadığı bildirilmiştir. Dispepsi, sağlık harcalamalarında önemli bir paya sahiptir ve hastaların yaşam kalitelerini önemli ölçüde etkileyen rahatsızlık olarak belirtilmiştir. ${ }^{3,4}$

Dispepsi hastalarının yüzde 75 'inde şikayetlerinin altında yatan organik bir neden yoktur ve fonksiyonel dispepsi olarak tanımlanır, yüzde 25 'inde ise organik bir neden bu şikayete yol açmaktadır. ${ }^{5}$ Dispepsi 2 başlık altında; fonksiyonel dispepsi ve organik dispepsi olarak 2 başılı altında değerlendirilebilinir. ${ }^{5}$

\section{Fonksiyonel Dispepsi}

Fonksiyonel yani idiyopatik veya ülser olmayan dispepsi tanısı, diğer organik dispepsi nedenlerinin dışlanması ile konmaktadır. Postprandiyal dolgunluk hissi, erken doyma, epigastrik ağrı veya yanma ile birlikte semptomları açıklayacak yapısal bir hastalık kanıtı yok ise fonksiyonel dispepsi tanısı konabilir. ${ }^{6}$

Fonksiyonel dispepsi tanı değerlendirmesi için 2016 yılında ROMA IV kriterleri tanımlanmıştır. ${ }^{7}$ Bunlar;

1) Aşağıdakilerden biri veya daha çoğu olacak

a. Postprandial dolgunluk (rahatsızlık)

b. Erken doyma (rahatsızlık)

c. Epigastrik ağrı (rahatsızlık)

d. Epigastrik yanma (rahatsızlık)

2) Semptomları açıklayacak yapısal hastalık için kanıt yoktur ve üst gastrointestinal sistem (GİS) endoskopisi nor- mal olmalıdır.

(Semptomlar başlangıcı tanı konmadan en az 6 ay önce olmalıdır ve son 3 aydır da tanı kriterlerini karşılayacak düzeyde semptomlar olmalıdır.)

Fonksiyonel dispepsi başlı̆̆ 1 postprandial distress sendromu ve epigastrik ağrı sendromu olarak ikiye ayrilır. Postprandial distress sendromu ise acı, 1zdırap, rahatsızlık sendromu olarak da adlandırılabilinir.?

Postprandiyal distres sendromu tanısı için aşağıdaki semptomlardan biri veya ikisi haftada en az 3 gün olmalıdır.

a. Postprandial dolgunluk hissi (rutin aktivitelerini etkileyecek kadar ciddi durumda)

b. Erken doyma hissi (normal miktarda yemeği bitiremeyecek kadar ciddi durumda)

Üst GİS endoskopisi dâhil yapılan tetkiklerde semptomları açılayacak organik, sistemik, metabolik hastalık kanıtı bulunmaması gereklidir. Semptomların başlangıcı tanı konmadan en az 6 ay önce olmalıdır ve son 3 aydır da her hafta en az 3 gün, 1 veya 2 semptomun da olması gereklidir.

Postprandial distress sendromu tanısını destekleyici bazı bulgular ise şunlardır.

i. Postprandial epigastrik ağrı, yanma, şişkinlik hissi ve geğirme, bulantı ile birlikte de görülebilir.

ii. Kusma eşlik ediyor ise başka bir hastalık olasılı̆̆ı mutlaka düşünülmelidir.

iii. Retrosternal yanma hissi (dispeptik bir semptom değildir ama sıklıkla eşlik edebilir.)

iv. Defekasyonla ve rektal gaz çıarmakla semptomlar düzeliyor ise dispepsi olarak yorumlanmamalıdır. Postprandial distress sendromu ile birlikte GÖRH (gastroözofajial reflü hastalığı) veya irritabl barsak sendromu (IBSS) olma olasılığının mutlaka akılda bulundurulması gerekir.

Epigastrik ağrı sendromu tanı kriterlerinde ise şunlar yer 
almaktadir. $^{7}$

Aşağıda belirtilen semptomlardan en az birinin haftada en az 1 gün olması gerekmektedir.

a. Sıkııı (bunaltıcı) şekilde olan epigastrik ağrı (rutin aktiviteleri etkileyecek kadar ciddi durumda)

b. Sıkıcı (bunaltıcı) şekilde olan epigastrik yanma (rutin aktiviteleri etkileyecek kadar ciddi durumda)

Organik, sistemik, metabolik bir hastalığı ortaya koyacak kanıt yoktur. Endoskopi dahil yapılan gerekli tetkik ve tahlillere rağmen semptomları açıklayacak bir kanıt olmaması gereklidir ve semptomların başlangıcı tanı konduktan en az 6 ay önce olmalıdır ve bunlara ilaveten hastanın son 3 aydır da haftada en az bir gün şikayet belirtmesi gerekmektedir.

Epigastrik ağrı sendromu tanısını destekleyici bazı bulgular şunlardır. ${ }^{7}$

i. Yemek yemekle ağrı ortaya çıkabilir, yemek yemekle var olan ağrı hafifleyebilir, ağrı açlık durumunda da ortaya çıkabilir.

ii. Postprandial dönemde epigastrik bölgede şişkinlik, geğirme hissi ve bulantı da görülebilir.

iii. İnatçı kusma varlığında başka bir hastalığın varlığını mutlaka düşünülmelidir.

iv. Retrosternal yanma hissi dispeptik bir semptom değildir. Fakat sıklıkla tabloya eşlik edebilir.

v. Dispepside ağrı biliyer ağrı karakterinden farklıdır.

vi. Semptomlar defekasyonla ve rektal gaz çıkarmakla düzeliyor ise dispepsi dışı irritabl barsak sendromu gibi başka bir tanı düşünülmelidir. Epigastrik ağrı sendromunun GÖRH ve İBS ile birlikte de olabileceği mutlaka akılda bulundurulmalıdır.

\section{Organik Dispepsi}

Dispepsinin ortaya çıkması için çeşitli organik nedenler mevcuttur. Ana nedenler olarak peptik ülser hastalığ 1 , gastroözofageal reflü hastalığı, ilaçlar (en çok suçlanan non-steroid anti-inflamatuar(NSAİ) ilaçlar) ve gastrik ma- ligniteler sayılabilir.8

Üst karın ağrısı veya rahatsızlığı, peptik ülseri olan hastalarda görülen en belirgin semptom dispepsidir. Peptik ülser hastalığıyla gelen hastada rahatsızlık genellikle epigastriumun ortasındadır fakat sağ veya sol üst kadranlara da lokalize olabilir.1 Duodenal ülserin klasik semptomları ise, bir mide içeriği yokluğunda (yani yemeklerden iki ila beş saat sonra veya aç karnına) asit salgılanırken ortaya çıksa da, peptik ülserler daha çok gıda kaynaklı semptomlarla ilişkilendirilebilir. Peptik ülserler ayrıca postprandiyal dönemde geğirme, epigastrik dolgunluk ve erken doyma hissi, yağlı gıdaya karşı gelişen intolerans tablosu, bulantı hissi ve ara sıra eşlik eden kusma ile de ilişkilendirilebilinir.

Gıda tüketimi ile dispepsi yakınmaları arasındaki ilişki değerlendirildiğinde baharatlar başta olmak üzere baklagillerin, soğanın, yağlı gıdaların, bulgur ve turşu gibi besinlerin hastaların şikayetlerini alevlendirdiği görülmektedir. Diyetin fonksiyonel dispepsi ve irritabl barsak sendromu gibi fonksiyonel gastrointestinal hastalıkların patogenez tablosunda rol oynadığ 1 öne sürülmekte olup laktoz, fruktoz, buğday ve kafein gibi gıdaların ise ön planda suçland1ğ1 görülebilmektedir. ${ }^{9}$

Gastroözofageal malignitelerin bir diğer dispepsi nedeni olduğu ve insidansının yaşla birlikte arttığı belirtilmiştir. ${ }^{10}$ Karın ağrısı şikayeti hastalığın erken dönemlerinde epigastrik bölgede yerleşim göstermektedir, belirsiz veya hafif derecede görülebilir; ancak hastalık ilerledikçe bu ağrı daha şiddetli ve sabit bir lokalizasyonda olma eğilimdedir. Anemi, yorgunluk, kilo kaybı gibi diğer semptomlar ve bulgular tipik olarak hastalığın ileriki dönemlerinde saptabilir. ${ }^{10}$

Dispepsi nedenleri arasında biliyer patolojiler de sayılabilir. Klasik biliyer ağrı, karın sağ üst kadranında, epigastriumda veya (daha az sıklıkla) arkaya yayılabilen substernal bölgede (özellikle sağ omuzda) bulunan epizodik karakterde yoğun ve künt ağrıdır. Ağrıya sıklıkla terleme, bu- 
lantı ve kusma eşlik edebilir. Ağrı sabittir ve kolik tarzda değildir. Hareketle şiddetlenmez ve çömelme, geğirme ile rahatlamaz. Ağrı tipik olarak en az 30 dakika sürer ve bir saat içinde yayılır. Daha sonra ağrı azalmaya başlar ve tüm ağrı süresi genellikle altı saatten az sürer. ${ }^{10}$

İlaç kullanımına bağlı olarak dispepsi şikayeti sıklıkla görülür. NSAİ ilaçlar ve siklooksijenaz-2 (COX-2) inhibitörleri, peptik ülser hastalığı olmasa bile dispepsi oluşturabilir. İlaca bağlı dispepsi ile ilişkili diğer ilaçlar arasında kalsiyum kanal blokörleri, metilksantin, alendronat, orlistat, potasyum takviyeleri, akarboz, dabigatran, demir, D vitamini, serotonin geri alım inhibitörleri, sildenafil, sülfonilüreler ve eritromisin dahil bazı antibiyotikler bulunur. ${ }^{11}$ Bazı hastalık tabloları sadece dispepsi şikayeti ile ortaya çıkabilmektedir. Bunlar arasında Çölyak hastalığı, kronik pankreatit, Crohn hastalığı, sarkoidoz, lenfoma ve amiloidoz sayılabilir. ${ }^{12,13}$

\section{Tanısal Değerlendirilme}

Dispepsi şikayeti ile başvuran hastanın değerlendirilmesinde ilk olarak anamnez, fizik muayene ve laboratuvar bulguları yer alır. Bu değerlendirmelerin asıl amacı, tanı yaklaşımını yönlendirecek gastroözofageal maligniteler için alarm bulgularını tanımlamaktır. ${ }^{10}$

Alarm bulguları ise; istenmeyen kilo kaybı, disfaji, odinofaji, nedeni bulunamayan demir eksikliği anemisi, sürekli olan inatçı kusma, fizik muayenede ele gelen kitle veya lenfadenopati, soygeçmişinde üst gastrointestinal malignite öyküsüdür. ${ }^{10}$

Şikayetin altında yatan nedeni belirlemek ve alarm bulguları olan hastaları tanımlamak için ayrıntılı bir anamnez almak gereklidir. Örneğin;

- Mide yanması ve regürjitasyon öyküsü olan hastada GÖRH ve fonksiyonel dispepsi tanılarının olduğu düşünülebilinir. ${ }^{14}$

- $\quad$ NSAİ ilaç kullanım öyküsü dispepsi ve peptik ülser hastalığı görülme olasılığını artırır.
- Ağrının sırta yayılması, özgeçmişinde ve soygeçmişinde pankreatit öyküsüne sahip olması, altta yatan kronik pankreatitin göstergesi olabilir.

- Tekrarlayan veya kalıcı şekilde olan üst karın ağrısı ile ortaya çıkan, kilo kaybı eşlik eden veya etmeyen, bulantı ve kusma şikayeti olan, özellikle risk faktörlerine sahip hastalarda gastroparezi görülme olasılığı fazladir.

- Kisa zaman diliminde önemli derecede olan kilo kayb1, anoreksi, kusma, disfaji, odinofaji ve ailede gastrointestinal malignite öyküsü, altta yatan bir gastroözofageal malignitenin olabileceğini düşündürmektedir.

- En az 30 dakika boyunca süren şiddetli epizodik karakterde olan epigastrik veya sağ üst kadranda olan karın ağrısının varlığı semptomatik kolelitiazis tablosunu akla getirmesi gerektiği belirtilmiştir. ${ }^{15}$

Laboratuvar testlerinde ayırıcı tanıya yönelik alarm bulguları gösterebilecek ve dispepsi oluşturabilecek altta yatan metabolik hastalıkları tanımlamak için hemogram, karaciğer fonksiyon testleri, serum lipaz ve amilaz dahil kan biyokimyası testleri yapılmalıdır. ${ }^{10}$

Dispepsi şikayeti olan bir hastaya yaklaşım ve hastalığın tanısal değerlendirmesinin yapılması klinik tabloya, hastanın yaşına ve alarm bulgularının varlığına dayandığı bildirilmiştir. ${ }^{7,16}$ (Şekil-1)

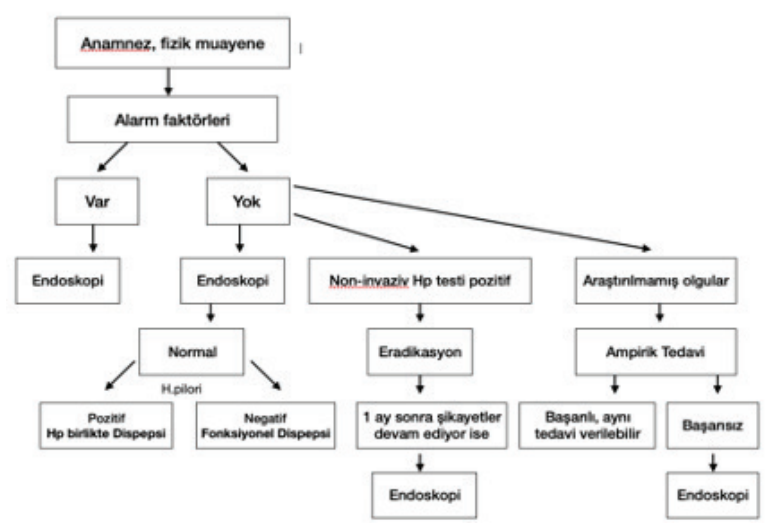

Şekil-1: Dispeptik yakınmaları olan hastaya klinik yaklaşım algoritmasi ${ }^{7}$ 
Dispepsi hastalarının tanısal değerlendirmesinde görülen semptomların yaş, etnik köken, aile öyküsü, uyruk ve bölgesel gastrik malignite insidansı temelinde değerlendirilmesi gereklidir.

Amerikan Gastroenteroloji Derneği kılavuzlarında, bazı ülkelerde 60 veya 65 yaşın, dispeptik hastalara endoskopinin yapılması gereken eşik yaş olarak kabul etmenin makul olabileceği; Asyalı, İspanyol veya Afro-Karayipli olan Amerika Birleşik Devletleri hastalarında veya gastrik malignite insidansının genç bireylerde fazla olduğu ülkelerde ise 45 veya 50 yaş aralığını eşik yaş olarak kabul etmenin makul olabileceği belirtilmektedir. ${ }^{10}$

Avrupa konsensusunun bildiriminde ise, dispepsi ile başvuran 45 yaşın üzerindeki erişkinlerde endoskopi yapılması önerilmektedir. ${ }^{17}$

Kriterleri karşılayan hastalarda dispepsiyi değerlendirmek için üst GIS endoskopisi yapılması ve helikobakter pilori'yi dışlamak için mideden biyopsi alınması önerilmektedir. Helikobakter pilori hastaları, altta yatan tanıya bağlı tedaviye ek olarak eradikasyon tedavisi almalıdırlar. ${ }^{18}$

5389 hastayla yapılan 9 çalışmanın bir meta-analizinde, dispepsi hastalarında en yaygın bulguların eroziv özofajit ve peptik ülser hastalığı olduğunu saptamıştır. ${ }^{19}$

Yaş durumundan bağımsız olarak belirtilen bazı kriterler endoskopik değerlendirmeyi hak etmektedir. Bunlar arasında klinik olarak anlamlı kilo kaybı (6 ila 12 ay süresince normal vücut ağırlığının yüzde 5'inden fazla) olan, gastrointestinal kanama geçiren, alarm semptomlarının birden fazla olması ve alarm bulgularında hızlı ilerleme olması sayılabilir. ${ }^{10}$

Dispepsi hastalarında Helikobakter pilori testinin yapılmasının nedeni, peptik ülser hastalığında etiyolojik bir faktör olarak Helikobakter pilori'nin yer almasına dayanmaktadır. Üst endoskopi gerektirmeyen veya üst endosko- pi sırasında biyopsinin alınamadığı hastalarda, Helikobakter pilori'nin saptanması aktif enfeksiyon testi ile üre nefes testi veya dışkıda antijen testi ile yapılmaktadır. Serolojik test düşük pozitif prediktif değeri nedeni ile genellikle kullanılmamaktadır. ${ }^{18}$

Helikobakter pilori enfeksiyonu için pozitif bulunan hastalara eradikasyon tedavisi uygulanmalıdır. Helikobakter pilori ile enfekte dispepsi şikayetleri olan 563 hastanın dahil edildiği randomize çalışmaların meta-analizinde eradikasyon tedavisinin plasebo ile karşılaştırıldığında, Helikobakter pilori eradikasyon tedavisinin dispepsi şikayetinde önemli bir azalmaya neden olduğu belirtilmiştir. ${ }^{20,21}$

\section{Tedavi Yaklaşımları}

Amerikan Gastroenteroloji Birliği (ACG) ve Kanada Gastroenteroloji Derneği (CAG) Helikobakter pilori eradikasyon tedavisinde ilk seçenek tedavisini aşağıdaki gibi önermektedir. $^{20}$

1. Bizmut $4 \times 1 /$ gün + Tetrasiklin $500 \mathrm{mg} \mathrm{3 \times 1/gün} \mathrm{+}$ Amoksisilin $500 \mathrm{mg}$ 4x1/gün (veya Metronidazol 500 mg 3x1/gün)

2. Bizmut $4 \times 1$ /gün + PPI $2 \times 1 /$ gün + Tetrasiklin $500 \mathrm{mg}$ 3x1/gün + Amoksisilin 500 mg 4x1/gün (veya Metronidazol $500 \mathrm{mg} 3 \times 1 /$ gün)

3. PPI 4x1/gün + Amoksisilin 500mg (veya750) mg 4x1/ gün

Bu seçeneklerdeki tedavilerin süresi 14 gün olmalıdır.

Proton pompa inhibitörleri (PPI) ile antisekretuar tedavi uygulanması dispepsi semptomlarının hafiflemesini sağlayabilir. $8 \mathrm{Bu}$, PPI tedavisi ile kontrol grubunun (plasebo veya anti-asit tedavi) karşılaştırıldığı 2709 dispepsi hastası içeren randomize kontrollü çalışmaların meta-analizinde gösterilmiştir. ${ }^{21}$ Dispepsi semptomları, kontrol grubuna kıyasla PPI kullanan grupta anlamlı derecede düşük bir oranda olduğu belirtilmiştir. PPI kullananların, H2 reseptör antagonistleri (H2RA) kullananlar ile karşılaştırıl- 
dığında dispepsi semptomlarını hafifletmede daha etkili olduğu öne sürülmüştür. 22,23 Çalışmalar, dispeptik semptomların hafifletilmesinde günde iki kez PPI kullanmanın daha etkili olmadığını göstermiştir. ${ }^{24}$

Birinci basamak hekimleri dispepsi tedavisinde önemli yer tutan diyet ve yaşam tarzının düzenlenmesi konularında hastaları bilgilendirmelidir. Az yemeleri, yağlı yiyeceklerden ve rahatsızlık tablosuna yol açan yiyeceklerden, içeceklerden uzak durmaları önerilmelidir. Öğünlerin miktarını az tutması ve altı ögün yemeleri tavsiye edilmelidir. Hastaların NSAİ ilaçlardan, kahve, alkol ve sigara tüketiminden sakınmaları gerektiği vurgulanmalıdır. ${ }^{7}$

Daha önce bahsedilen Helikobakter pilori ve mide asit süpresyon tedavisine ek olarak mukoza koruyucu ajanlar ve prokinetikler kullanılabilir. ${ }^{25}$

Mukoza koruyucu ajanlar; bizmut subsalisilat, antasidler, sükralfat ve misprostolün bazı çalışmalarda plasebodan daha etkili olduğunu gösterilmiştir. ${ }^{25}$

Prokinetikler grubunu ise metoklopramide, domperidon, sisaprid, eritromisin ve fedotozin gibi ajanlar oluşturur. Sisaprid kan seviyesindeki yükseklikte kalpte aritmilerine yol açtığından ülkemizde kullanılmamaktadır. ${ }^{26}$ Domperidon idiopatik gastroparezi ve fonksiyonel dispepsisi olan hastalarda semptomlarda iyileşmeye yol açabilir fakat mide boşalması üzerine etkisi tartışmalı olan bir konudur. Metoklopramid etken maddesi ise kullanılan eski ve yaygin bir ajandır. Santral ve periferal D2 antagonisti, gastrokinetik ve anti-emetik etkili bir ajandır. Kan-beyin bariyerini geçebildiği için bazı yan etkiler neden olmaktadır. ${ }^{27}$ Trisiklik antidepresanlar ve psikoterapi seçeneğinin de hastalığın tedavi seçenekleri arasında olması gerektiği belirtilmiştir. ${ }^{20}$

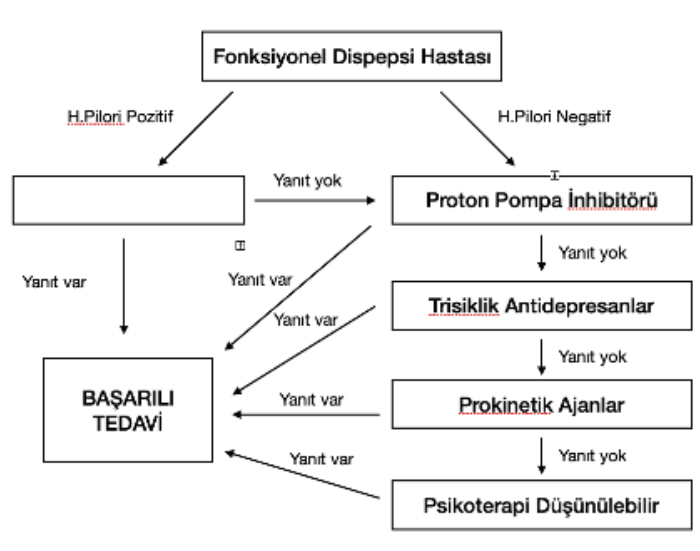

Şekil-2: Fonksiyonel Dispepsi hastasında tedavi yaklaşım algoritmas $^{20}$

\section{SONUÇ}

Birinci basamakta dispepsi şikayeti ile başvuran erişkin hastada izlenecek yollar literatür eşliğinde anlatılmaya çalışılmıştır. Dispepsi şikayetiyle başvuran hastanın alarm semptomlarına sahip olup olmadığı mutlaka sorgulanmalıdır. Birçok organik hastalığın tek belirtisi dispepsi olabileceğinden şüphenilen durumda mutlaka endoskopik değerlendirme ve ileri tetkik için üst basamağa ilgili uzman hekimine yönlendirilmelidir. 
Sakarya Tıp Dergisi 2020;10(Özel Sayı):69-75

ETÇioĞLU ve Ark., Dispepsiye Klinik Yaklaşım

\section{Kaynaklar}

1. Talley NJ, Silverstein MD, Agreus L, Nyren O, Sonnenberg A, Holtmann G. AGA technical review: evaluation of dyspepsia. Gastroenterology 1998;114:582-595.

2. Uslan İ, Ellidokuz E. Birinci Basamakta Dispepsiye Güncel Yaklaşım. Sürekli Tip Eğitimi Dergisi 2003; 12(6):216.

3. Lacy BE, Weiser KT, Kennedy AT, et al. Functional dyspepsia: the economic impact to patients. Aliment Pharmacol Ther 2013; 38:170.

4. Köksal A, Oğuz D, Özden A. Türkiye’de birinci basamak sağllk kurumlarna bașvuran hastalarda dispepsi görülme sıklğğ. Akademik Gastroenteroloji Dergisi 2008; 7(1): 11-17.

5. Bytzer P, Talley NJ. Dyspepsia. Ann Intern Med 2001; 134:815.

6. Lacy BE, Talley NJ, Locke GR 3rd, et al. Review article: current treatment options and management of functional dyspepsia. Aliment Pharmacol Ther 2012; 36:3.

7. Özden A. Roma IV-2016, Dispepsi Tedavisine Yaklaşım. Güncel Gastroenteroloji 2017; 21(1): 19-24.

8. Kavitt RT, Lipowska AM, Anyane-Yeboa A, Gralnek IM. Diagnosis and Treatment of Peptic Ulcer Disease. Am J Med 2019; 132:447.

9. Feinle-Biset C, Vozzo R, Horowitz M, et al. Diet, food intake, and disturbed physiology in the pathogenesis of symptoms in functional dyspepsia. Am J Gastroenterol 2004; 99:170-81.

10. Talley NJ, Vakil NB, Moayyedi P. American gastroenterological association technical review on the evaluation of dyspepsia. Gastroenterology 2005; 129:1756.

11. Hallas J, Bytzer P. Screening for drug related dyspepsia: an analysis of prescription symmetry. Eur J Gastroenterol Hepatol 1998; 10:27.

12. Brito-Zerón P, Bari K, Baughman RP, Ramos-Casals M. Sarcoidosis Involving the Gastrointestinal Tract: Diagnostic and Therapeutic Management. Am J Gastroenterol 2019; 114:1238.

13. Juárez-Salcedo LM, Sokol L, Chavez JC, Dalia S. Primary Gastric Lymphoma, Epidemiology, Clinical Diagnosis, and Treatment. Cancer Control 2018; 25.

14. Moayyedi P, Axon AT. The usefulness of the likelihood ratio in the diagnosis of dyspepsia and gastroesophageal reflux disease. Am J Gastroenterol 1999; 94:3122.
15. Thistle JL, Longstreth GF, Romero Y, et al. Factors that predict relief from upper abdominal pain after cholecystectomy. Clin Gastroenterol Hepatol 2011; 9:891.

16. Hunt RH, Xiao SD, Megraud F, et al. Helicobacter pylori in developing countries. World Gastroenterology Organisation Global Guideline. J Gastrointestin Liver Dis 2011; 20:299.

17. Malfertheiner P, Megraud F, O'Morain C, et al. Current concepts in the management of Helicobacter pylori infection: the Maastricht III Consensus Report. Gut 2007; 56:772.

18. Malfertheiner P, Megraud F, O'Morain CA, et al. Management of Helicobacter pylori infection--the Maastricht IV/ Florence Consensus Report. Gut 2012; 61:646.

19. Ford AC, Marwaha A, Lim A, Moayyedi P. What is the prevalence of clinically significant endoscopic findings in subjects with dyspepsia? Systematic review and meta-analysis. Clin Gastroenterol Hepatol 2010; 8:830.

20. Moayyedi P, Lacy BE, Andrews CN, et al. ACG and CAG Clinical Guideline: Management of Dyspepsia. Am J Gastroenterol 2017; 112:988.

21. Chey WD, Leontiadis GI, Howden CW, Moss SF. ACG Clinical Guideline: Treatment of Helicobacter pylori Infection. Am J Gastroenterol 2017; 112:212.

22. Jones RH, Baxter G. Lansoprazole $30 \mathrm{mg}$ daily versus ranitidine $150 \mathrm{mg}$ b.d. in the treatment of acid-related dyspepsia in general practice. Aliment Pharmacol Ther 1997; 11:541.

23. Mason I, Millar LJ, Sheikh RR, et al. The management of acid-related dyspepsia in general practice: a comparison of an omeprazole versus an antacid-alginate/ranitidine management strategy. Compete Research Group [corrected]. Aliment Pharmacol Ther 1998; 12:263.

24. Talley NJ, Lauritsen K. The potential role of acid suppression in functional dyspepsia: the BOND, OPERA, PILOT, and ENCORE studies. Gut 2002; 50 Suppl 4:iv36.

25. Moayyedi P, Soo S, Deeks J, Delaney B, Innes M, Forman D. Pharmacological interventions for non-ulcer dyspepsia. Cochrane Database Syst Rev 2006; (4): CD001960.

26. Kligler B, Chaudhary S. Peppermint oil. Am Fam Physician 2007;75(7): 1027-30.

27. Holtmann G, Gschossmann J, Mayr P, Talley NJ. A randomized placebo-controlled trial of simethicone and cisapride for the treatment of patients with functional dyspepsia. Aliment Pharmacol Ther 2002;16(9): 1641-8. 